\title{
Perinatal $\mathrm{Pb}^{2+}$ exposure alters the expression of genes related to the neurodevelopmental GABA-shift in postnatal rats
}

\author{
Lorenz S. Neuwirth ${ }^{1,2,3,4,5^{*}}$ (D), Greg R. Phillips ${ }^{3,4,5}$ and Abdeslem El Idrissi $i^{3,4,5}$
}

\begin{abstract}
Background: Lead $\left(\mathrm{Pb}^{2+}\right)$ is an environmental neurotoxicant that disrupts neurodevelopment, communication, and organization through competition with $\mathrm{Ca}^{2+}$ signaling. How perinatal $\mathrm{Pb}^{2+}$ exposure affects $\mathrm{Ca}^{2+}$-related gene regulation remains unclear. However, $\mathrm{Ca}^{2+}$ activates the L-Type voltage sensitive calcium channel $\beta-3$ subunit (Ca- $\beta 3)$, which autoregulates neuronal excitability and plays a role in the GABA-shift from excitatory-toinhibitory neurotransmission.

Method: A total of eight females ( $n=4$ Control and $n=4$ Perinatal) and four males ( $n=2$ Control and $n=2$ Perinatal) rats were used as breeders to serve as Dams and Sires. The Dam's litters each ranged from $N=6-$ 10 pups per litter $(M=8, S D=2)$, irrespective of $\mathrm{Pb}^{2+}$ treatment, with a majority of males over females. Since there were more males in each of the litters than females, to best assess and equally control for $\mathrm{Pb}^{2+}-$ and litter-effects across all developmental time-points under study, female pups were excluded due to an insufficient sample size availability from the litter's obtained. From the included pup litters, 24 experimentally naïve male Long Evans hooded rat pups (Control $N=12 ; \mathrm{Pb}^{2+} \mathrm{N}=12$ ) were used in the present study. Brains were extracted from rat prefrontal cortex (PFC) and hippocampus (HP) at postnatal day (PND) 2, 7, 14 and 22, were homogenized in $1 \mathrm{~mL}$ of TRlzol reagent per $100 \mathrm{mg}$ of tissue using a glass-Teflon homogenizer. Postcentrifugation, RNA was extracted with chloroform and precipitated with isopropyl alcohol. RNA samples were then re-suspended in $100 \mu \mathrm{L}$ of DEPC treated $\mathrm{H}_{2} \mathrm{O}$. Next, $10 \mu \mathrm{g}$ of total RNA was treated with RNase-free DNase (Qiagen) at $37{ }^{\circ} \mathrm{C}$ for $1 \mathrm{~h}$ and re-purified by a 3:1 phenol/chloroform extraction followed by an ethanol precipitation. From the purified RNA, $1 \mu \mathrm{g}$ was used in the SYBR GreenER Two-Step qRT-PCR kit (Invitrogen) for first strand cDNA synthesis and the quantitative real-time PCR (qRT-PCR). The effects of perinatal $\mathrm{Pb}^{2+}$ exposure on genes related to early neuronal development and the GABA-shift were evaluated through the expression of: $\mathrm{Ca}-\beta 3, \mathrm{GABA}_{A R}-\beta 3, \mathrm{NKCC}_{1}, \mathrm{KCC}_{2}$, and $\mathrm{GAD} 80,86,65$, and 67 isoforms.

(Continued on next page)
\end{abstract}

\footnotetext{
* Correspondence: NeuwirthL@Oldwestbury.edu

${ }^{1}$ Department of Psychology, SUNY Old Westbury, 223 Store Hill Road, Bldg:

NAB, Room: 2059, Old Westbury, NY 11568-1700, USA

${ }^{2}$ SUNY Old Westbury, Neuroscience Research Institute, 223 Store Hill Road,

Bldg.: NAB, Room: 2059, Old Westbury, NY 11568-1700, USA

Full list of author information is available at the end of the article
}

(c) The Author(s). 2018 Open Access This article is distributed under the terms of the Creative Commons Attribution 4.0 International License (http://creativecommons.org/licenses/by/4.0/), which permits unrestricted use, distribution, and reproduction in any medium, provided you give appropriate credit to the original author(s) and the source, provide a link to the Creative Commons license, and indicate if changes were made. The Creative Commons Public Domain Dedication waiver (http://creativecommons.org/publicdomain/zero/1.0/) applies to the data made available in this article, unless otherwise stated. 
(Continued from previous page)

Results: Perinatal $\mathrm{Pb}^{2+}$ exposure significantly altered the GABA-shift neurodevelopmental GOI expression as a function of $\mathrm{Pb}^{2+}$ exposure and age across postnatal development. Dramatic changes were observed with Ca- $\beta 3$ expression consistent with a $\mathrm{Pb}^{2+}$ competition with L-type calcium channels. By PND 22, Ca- 33 mRNA was reduced by 1 -fold and 1.5-fold in PFC and HP respectively, relative to controls. All HP GABA- $\beta 3$ mRNA levels were particularly vulnerable to $\mathrm{Pb}^{2+}$ at PND 2 and 7, and both PFC and HP were negatively impacted by $\mathrm{Pb}^{2+}$ at PND 22. Additionally, $\mathrm{Pb}^{2+}$ altered both the PFC and HP immature GAD 80/86 mRNA expression particularly at PND 2, whereas mature GAD 65/67 were most significantly affected by Pb ${ }^{2+}$ at PND 22.

Conclusions: Perinatal $\mathrm{Pb}^{2+}$ exposure disrupts the expression of mRNAs related to the GABA-shift, potentially altering the establishment, organization, and excitability of neural circuits across development. These findings offer new insights into the altered effects $\mathrm{Pb}^{2+}$ has on the GABAergic system preceding what is known regarding $\mathrm{Pb}^{2+}$ insults unto the glutamatergic system.

Keywords: GABA-shift, Lead exposure, Neurodevelopment, Neurotoxicant, mRNA patterns, Prefrontal cortex, Hippocampus, Postnatal development, L-type calcium channels, Frontoexecutive dysfunction

\section{Background}

Lead $\left(\mathrm{Pb}^{2+}\right)$ is a well-established environmental neurotoxicant, which at low levels of exposure causes deleterious effects to neurodevelopment. The immature brain is particularly vulnerable to $\mathrm{Pb}^{2+}$ given that young mammals have a higher absorption of minerals than adults [1], as well as the fact that the blood brain barrier is still developing [2]. $\mathrm{Pb}^{2+}$ exposure dose-dependently induces brain region specific effects on transcriptome gene expression [3, 4]. Moreover, behaviorally naive rats exposed developmentally to $\mathrm{Pb}^{2+}$ show sex-based altered gene expression changes in the HP of aged rats [5], suggesting that perinatal exposure can disrupt genetic programs in the absence of sensory and behavioral experience. These studies are consistent with neurodevelopmental $\mathrm{Pb}^{2+}$ exposure altering later life cognitive outcomes damaging the prefrontal cortex (PFC) and hippocampus (HP) as a function of gender and time-period of exposure.

Notably, most studies investigating neurodevelopmental $\mathrm{Pb}^{2+}$ exposure restricted their focus to adult outcomes [3-8] warranting earlier investigation of the underlying mechanisms producing this developmental neuropathology. Interestingly, even low blood lead levels (BLLs) can produce frontoexecutive dysfunctions and neuropathologies in children, which persist across the lifespan $[2,9,10]$. This highlights the need for early biomarkers of neuropathological disease that can predict developmental $\mathrm{Pb}^{2+}$ exposure problems early in postnatal life and that can be tracked across the lifespan. For example, $\mathrm{Pb}^{2+}$ exposure alters the levels of hippocampal NMDA receptor mRNA transcription and translation with associated learning and memory defects in adult rodents [3-8].

It is likely that perinatal $\mathrm{Pb}^{2+}$ exposure alters the expression of additional genes related to synaptic connectivity and function given the widespread effect of $\mathrm{Pb}^{2+}$ on the neurodevelopmental transcriptome [3, 4]. One possible mechanism by which $\mathrm{Pb}^{2+}$ might affect neurodevelopment is during the "GABA-shift" [11]. The GABA-shift is a crucial neurodevelopmental event in which GABA is converted from an excitatory to an inhibitory neurotransmitter. The initial depolarizing effect of GABA is due to the high intracellular concentration of chloride ions during the early postnatal period. Thus, the GABA-shift is an important neurodevelopmental event that plays a crucial role in activating and wiring the neural circuitry necessary for lifelong learning and memory [11]. Alterations in the levels of genes that regulate the GABA-shift could result in developmental neuropathological disorders [12]. In particular, the beta- 3 subunit of the L-Type voltage sensitive calcium channel (Ca- $\beta 3$ ), has been shown to autoregulate its own channel activity through excitation-transcription coupling as a function of neuronal excitability [13]. Since the Ca- $\beta 3$ subunit has been shown to be responsible for driving gene expression in neurons, especially in early development when most other neurotransmitter systems are either less expressed of functionally inactive, the Ca- $\beta 3$ expression levels naturally occurring in development serve a unique role in regulating the dynamic function of neuronal activity. This $\mathrm{Ca}-\beta 3$ functional regulation of gene expression different from the L-Type voltage sensitive calcium channel alpha-1 subunit (Ca- $\alpha 1)$ pore forming subunits, that regulate neuronal activity and less of gene expression $[13,14]$. Moreover, Ca- $\alpha 1$ have been shown to be disrupted by $\mathrm{Pb}^{2+}$, yet less is known regarding its impacts on Ca- $\beta 3$ and how $\mathrm{Pb}^{2+}$ may affect gene expression related to the GABA-shift. We therefore investigated the effects of perinatal $\mathrm{Pb}^{2+}$ exposure on the neurodevelopmental patterns of the genes regulating the GABA-shift in rat prefrontal cortex (PFC) and hippocampus (HP) during the time-frame spanning the GABA-shift. The genes of interest (GOI) were as follows: the beta-3 subunit of the L-Type voltage sensitive calcium channel (Ca- $\beta 3)$, the $\gamma$-amino butyric acid receptor A-beta-3 receptor subunit (GABA- $\beta 3$ ); the $\mathrm{Na}^{+}-\mathrm{K}^{+}-\mathrm{Cl}^{-} \mathrm{Cl}^{-}$ 
cotransporter $\left(\mathrm{NKCC}_{1}\right)$; the $\mathrm{K}^{+}-\mathrm{Cl}^{-} \mathrm{Cl}^{-}$cotransporter potassium/chloride co-transporter-1 $\left(\mathrm{KCC}_{2}\right)$; and glutamic acid decarboxylase (GAD) early 80/86 and late 65/67 isoforms. We found that perinatal $\mathrm{Pb}^{2+}$ exposure alters the expression of these genes in a way that could have an impact on the timing and magnitude of the GABA-shift.

\section{Method}

\section{Subjects}

One month prior to pairing 10-14 week old behaviorally naïve Long Evans Hooded rats $(N=12)$ purchased from (Taconic, NJ) were randomly selected for breeding from to establish an in-house breeding colony to be designated as either receiving Control or Perinatal $\mathrm{Pb}^{2+}$ treatments, respectively. A total of eight females $(n=4$ Control and $n=4$ Perinatal) and four males ( $n=2$ Control and $n=2$ Perinatal) rats were used as breeders to serve as Dams and Sires. The Dam's litters each ranged from $N=6-10$ pups per litter $(M$ $=8, S D=2$ ), irrespective of $\mathrm{Pb}^{2+}$ treatment, with a majority of males over females. Since there were more males in each of the litters than females, to best assess and equally control for $\mathrm{Pb}^{2+}$ - and litter-effects across all developmental time-points under study, female pups were excluded due to an insufficient sample size availability from the litter's obtained. From the included pup litters, 24 experimentally naïve male Long Evans hooded rat pups (Control $N=12$; $\mathrm{Pb}^{2+} N=12$ ) were sacrificed under the College of Staten Island IACUC approval procedures. Rats were maintained under controlled temperature $\left(24 \pm 1{ }^{\circ} \mathrm{C}\right)$ and humidity (55 $\pm 5 \%)$, on a $12 \mathrm{~h}: 12 \mathrm{~h}$ light: dark reversed cycle.

\section{Experimental design and procedures}

The breeders were paired as two female Dams with one male Sire for 3 weeks as a timed pregnancy, which was assessed upon observation of the Dam's copulatory plug. Following the 3 weeks of pregnancy, the Dams were then separated into individual cages from the Sires. Once the pups were born, which was defined as postnatal day (PND) 0, male pups were randomly sampled by selecting one male pup from each litter at each developmental time-point (i.e., PND 2, 7, 14, and 22) to control for any individual litter effects as an extraneous variable. Thus, for each developmental time-point an $(N=6)$ pups were sacrificed, brain regions of interest removed, and subsequently used for mRNA analysis.

\section{Materials and $\mathrm{Pb}^{2+}$ administration}

Control Dams were administered Purina RMH 1000 chow (Dyets, Inc.) absent of any lead source ad libitium for the duration of the experiment. In contrast, Lead treated Dams were administered the same food with lead acetate that was commercially engineered within the Purina RMH 1000 chow (Dyets, Inc.) containing $30 \mathrm{~g} / \mathrm{kg}$ maltose dextrin, $1.5 \mathrm{~g} / \mathrm{kg} \mathrm{Pb}^{2+}\left(\mathrm{C}_{2} \mathrm{H}_{3} \mathrm{O}_{2}\right)_{2}$, and $0.1 \mathrm{~g} / \mathrm{kg}$ yellow dye], which reflected a $996 \mathrm{ppm}$ lead acetate exposure. Thus, Dams were administered lead acetate through their only food source ad libitium from 2 weeks prior to pairing and continued throughout gestation until the sacrifice of their pups at each developmental time-point (i.e., PND 2, 7, 14, and 22) defining a perinatal period of exposure (i.e., - PND 34 to PND 22). At PND 0 when the pups were born, they were continually administered lead acetate via the Dam's lactation as their source of $\mathrm{Pb}^{2+}$ exposure from PND 0 to PND 13. When the rat pups were able to each from the food hopper independently at PND 14 to PND 22, they then obtained $\mathrm{Pb}^{2+}$ exposure from two sources, both the Dam's lactation and the food ad libitium.

\section{Blood lead level analyses}

At the indicated PND of development time-point sacrifice, blood samples were collected with a $2 \mathrm{~mL}$ anti-coagulant EDTA coated syringes (Sardstedt, Germany), mixed to prevent coagulation, and then frozen at ${ }^{-} 80^{\circ} \mathrm{C}$. Blood samples were sent out for commercial analysis by Magellan Diagnostics (North Billerica, MA) to determine the amount of lead in the blood by electrochemical anodic stripping voltammetry (ASV) to eliminate any potential for experimenter bias. Briefly, the ASV procedure lyses red blood cells (RBCs) so that $\mathrm{Pb}^{2+}$ are liberated. Then a negative electrochemical potential that was pre-applied to the test sensor strip was used to attract and aggregate the $\mathrm{Pb}^{2+}$ ions as a reduction step. Sequentially, an oxidation reaction was used to strip the aggregated $\mathrm{Pb}^{2+}$ ions by reversing the sample to a positive electrochemical potential and the amount of $\mathrm{Pb}^{2+}$ was then determined from the sample volume and calculated as the area under the curve. Therefore, the blood lead levels (BLLs) were processed using the ASV method by taking $50 \mu \mathrm{L}$ of whole blood mixed with $250 \mu \mathrm{L}$ of hydrochloric acid solution $(0.34 \mathrm{M})$ and then applying the final mixture to the lead sensor strip and inserted into an ESA LeadCare II Blood Lead Analyzer system (Magellan Diagnostics, North Billerica, MA). After $3 \mathrm{~min}$, the BLLs were reported from the instrument in $\mu \mathrm{g} / \mathrm{dL}$ with lower sensitivity cut off value of $3 \mu \mathrm{g} / \mathrm{dL}$ and a high sensitivity cut off value of $65 \mu \mathrm{g} / \mathrm{dL}$, with a standard error sensitivity detection level of $\pm 1.5 \mu \mathrm{g} / \mathrm{dL}$. If a BLL value were to occur below the lower limit, it was reported as $<3 \mu \mathrm{g} / \mathrm{dL}$ and if a BLL value were to occur above the higher limit, it was reported as $>65 \mu \mathrm{g} / \mathrm{dL}$. Once all samples were commercially processed, the BLL data reports were generated and sent back to the researchers.

\section{Tissue sample collections}

At PND 2, 7, 14 and 22 rats were randomly sampled from three different litters for each treatment condition, 
Table 1 Oligonucleotides used in the real-time qRT-PCR reactions

\begin{tabular}{ll}
\hline GAPDH ORF & \\
Forward primer & 5'-ACAGGGTGGTGGACCTCATG-3' \\
Reverse primer & 5'-GTTGGGATAGGGCCTCTCTTG-3' \\
GABA $_{\text {A } 33 \text { ORF }}$ & \\
Forward primer & 5'-CCACGGAGTGACAGTGAAAA-3' \\
Reverse primer & 5'-CACGCTGCTGTCGTAGTGAT-3' \\
CACNB $\beta 3$ ORF & \\
Forward primer & 5'-TGGATCGGGAGGCTAGTGAA-3' \\
Reverse primer & 5'-CACGCTGCTCGTAGTGAT-3' \\
NKCC 1 ORF & \\
Forward primer & 5'-ATGAGTCTTCCAGTTGCCCG-3' \\
Reverse primer & 5'-GCAACGTGTCCATGTGCTTT-3' \\
KCC 2 ORF & \\
Forward primer & 5'-GGACCCCCGCATACAAAGAA-3' \\
Reverse primer & 5'-CCTCCAGACCTTGTGGTGAC-3' \\
GAD 80 ORF & \\
Forward primer & 5'-AGTGTGGCCTCCAGAGGTTC-3' \\
Reverse primer & 5'-TGGATATGGCTCCCCCAGGAG-3' \\
GAD 86 ORF & 5'-GGCTCTGGCTTTTGGTCCTTC -3' \\
Forward primer & 5'-TGGCCTCCAGAGGTGATGGT -3' \\
Reverse primer & \\
FAD 65 ORF & \\
Forward primer & \\
Reverse primer & \\
\hline & \\
\hline
\end{tabular}

sacrificed, and their frontal cortices and hippocampi extracted under two-minutes, frozen, and stored at ${ }^{-} 80^{\circ} \mathrm{C}$.

\section{RNA preparation}

The PFC and HP total RNA was prepared using TRIzol Reagent (Invitrogen) consistent with our prior work [15, 16]. Briefly, 50-60 mg of wet brain tissues were homogenized in $1 \mathrm{~mL}$ of TRIzol reagent per $100 \mathrm{mg}$ of tissue using a glass-Teflon homogenizer. Post-centrifugation, RNA was extracted with chloroform and precipitated with isopropyl alcohol. RNA samples were then re-suspended in $100 \mu \mathrm{L}$ of DEPC treated $\mathrm{H}_{2} \mathrm{O}$.

\section{Preparation of CDNA and quantitative real-time PCR analysis}

Next, $10 \mu \mathrm{g}$ of total RNA was treated with RNase-free DNase (Qiagen) at $37{ }^{\circ} \mathrm{C}$ for $1 \mathrm{~h}$ and re-purified by a 3:1 phenol/chloroform extraction followed by an ethanol precipitation. From the purified RNA, $1 \mu \mathrm{g}$ was used in the SYBR GreenER Two-Step qRT-PCR kit (Invitrogen) for first strand CDNA synthesis and the quantitative real-time PCR (qRT-PCR). The qRT-PCR primers are listed in Table 1. All experiments were performed in triplicates and repeated twice for each experiment. All qRT-PCR reactions were analyzed through an ABI 7500 sequence detection system (Applied Biosystems).

\section{Target DNA sequence estimations}

Target DNA sequence quantities were estimated using Zhang et al. [15] and Shen et al. [16] procedures. Briefly, the target DNA sequence quantities were estimated from the threshold amplification cycle number $\left(C_{T}\right)$ using a 7500 Sequence Detection System Software. The $\Delta C_{T}$ values were obtained by subtracting the respective GOI primer $C_{T}$ values from the corresponding housekeeping gene glyceraldehyde 3-phosphate dehydrogenase (GAP DH) $C_{T}$ values to normalize the cDNA differences. Relative mRNA levels were expressed as $2^{(-\Delta C T)} \mathrm{X} 100 \%$ of GAPDH. Data were then transformed using a $\log _{10}$ calculation to assess relative fold changes across all GOIs under investigation to characterize their neurodevelopmental expression patterns as a function of age, treatment, and brain region.

\section{Statistical analyses}

Data were analyzed with IBM SPSS version 24. A multi-factorial ANOVA with a Tukey's HSD post hoc comparisons test and a partial Eta squared $\left(\eta_{p}^{2}\right)$ were used to assess Age, Treatment, and Age X Treatment interaction effects for each GOI per brain region. Significance levels were set at $\alpha=0.05$ and a CI of $95 \%$. Data are presented as the mean \pm SEM for both BLLs and all mRNA comparisons.

\section{Results}

\section{Pup and dam BLLs}

BLLs were determined from the pups and dams simultaneously. The average pup BLL was $44.67 \mu \mathrm{g} / \mathrm{dL}$ (SEM $=0.48 ; n=4), 36.00 \mu \mathrm{g} / \mathrm{dL}(S E M=0.63 ; n=4), 30.33 \mu \mathrm{g} /$ $\mathrm{dL}(S E M=0.67 ; n=4)$, and $37.33 \mu \mathrm{g} / \mathrm{dL}(S E M=0.58 ; n$ =4) for PND 2, 7, 14 and 22 respectively. The average dam BLL was $37.00 \mu \mathrm{g} / \mathrm{dL}(S E M=0.58 ; n=4), 41.33 \mu \mathrm{g} /$ $\mathrm{dL}(S E M=0.72 ; n=4), 39.33 \mu \mathrm{g} / \mathrm{dL}(S E M=0.93 ; n=4)$, and $43.67 \mu \mathrm{g} / \mathrm{dL}(S E M=0.86 ; n=4)$ for dams at PND 2, 7, 14 and 22, respectively. All control dams and pups were $\mathrm{Pb}^{2+}$ negative. Notably, the Dam's nor the pup's body weights were not significantly different from one another at each developmental time-point as a function of $\mathrm{Pb}^{2+}$ lead treatment (data not shown). 


\section{$\mathrm{Pb}^{2+}$ effects on $\mathrm{Ca} \beta 3$ and GABA- $\beta 3$ mRNA}

Postnatal changes in the expression of the potassium/ chloride co-transporter $\left(\mathrm{KCC}_{2}\right)$ and the sodium/potassium chloride co-transporter $\left(\mathrm{NKCC}_{1}\right)$ regulate the GABA-shift from excitatory-to-inhibitory neurotransmission. Perinatal $\mathrm{Pb}^{2+}$ exposure could disrupt this shift by its action on L-type calcium channels and downstream effects on $\mathrm{KCC}_{2}$ and $\mathrm{NKCC}_{1}$ expression levels. We therefore compared pup brain mRNA expression levels of Ca- $\beta 3, \mathrm{NKCC}_{1}, \mathrm{KCC}_{2}$, GABA- $\beta 3$, GAD 80/86, and 65/67 from control and maternally $\mathrm{Pb}^{2+}$ exposed rats at various time points after birth.

In $\mathrm{PFC}, \mathrm{Ca}-\beta 3$ was dynamically regulated during postnatal development in control animals, decreasing in expression by nearly 1.5 fold as an Age effect between PND 2 and $7 F_{(3,20)}=24.51, p<0.001^{* * * *}, \quad \eta_{p}^{2}=0.821$ (Fig. 1a). Expression levels recovered between PND 7 and 14 , and then decreased slightly at PND 22. Perinatal $\mathrm{Pb}^{2+}$ exposure completely blunted this regulation with $\mathrm{Ca}-\beta 3$ at similar levels initially at PND 2 , with a gradual decrease in expression over the time course evidencing an Age $X$ Treatment interaction $F_{(3,1,20)}=17.03$, $p<0.001^{\text {帮}}, \eta_{p}^{2}=0.762$. Contrastingly, in HP, Ca- $\beta 3$ mRNA exhibited an Age effect as a steady gradual decline in levels from PND 2 to $22 F_{(3,20)}=17.46$, $p<0.001^{* * * *}, \quad \eta_{p}^{2}=0.766$ (Fig. 2b). $\mathrm{Pb}^{2+}$ exposure decreased the expression levels of $\mathrm{Ca}-\beta 3$ at each time point with a significant Treatment effect $F_{(1,20)}=49.27$,

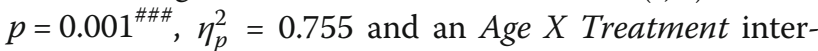
action $F_{(3,1,20)}=5.28, p=0.01^{\text {米}}, \eta_{p}^{2}=0.498$. Thus, these results suggest that $\mathrm{Pb}^{2+}$ exposure causes the neurodevelopmental misregulation of $\mathrm{Ca}-\beta 3$ in both PFC and HP.

In PFC, GABA- $\beta 3$ (Fig. 1c), similar to $\mathrm{Ca} \beta 3$, was dynamically regulated in control animals with increased expression at PND 2 and 14 and reduced expression at PND 7 and 22 as an Age effect $F_{(3,20)}=98.01$, $p<0.001^{* * * *}, \eta_{p}^{2}=0.948$. Treatment with $\mathrm{Pb}^{2+} F_{(1,20)}=7.08$, $p<0.02^{\#}, \eta_{p}^{2}=0.307$ significantly altered this regulation in a manner distinct from that in the control pups and further
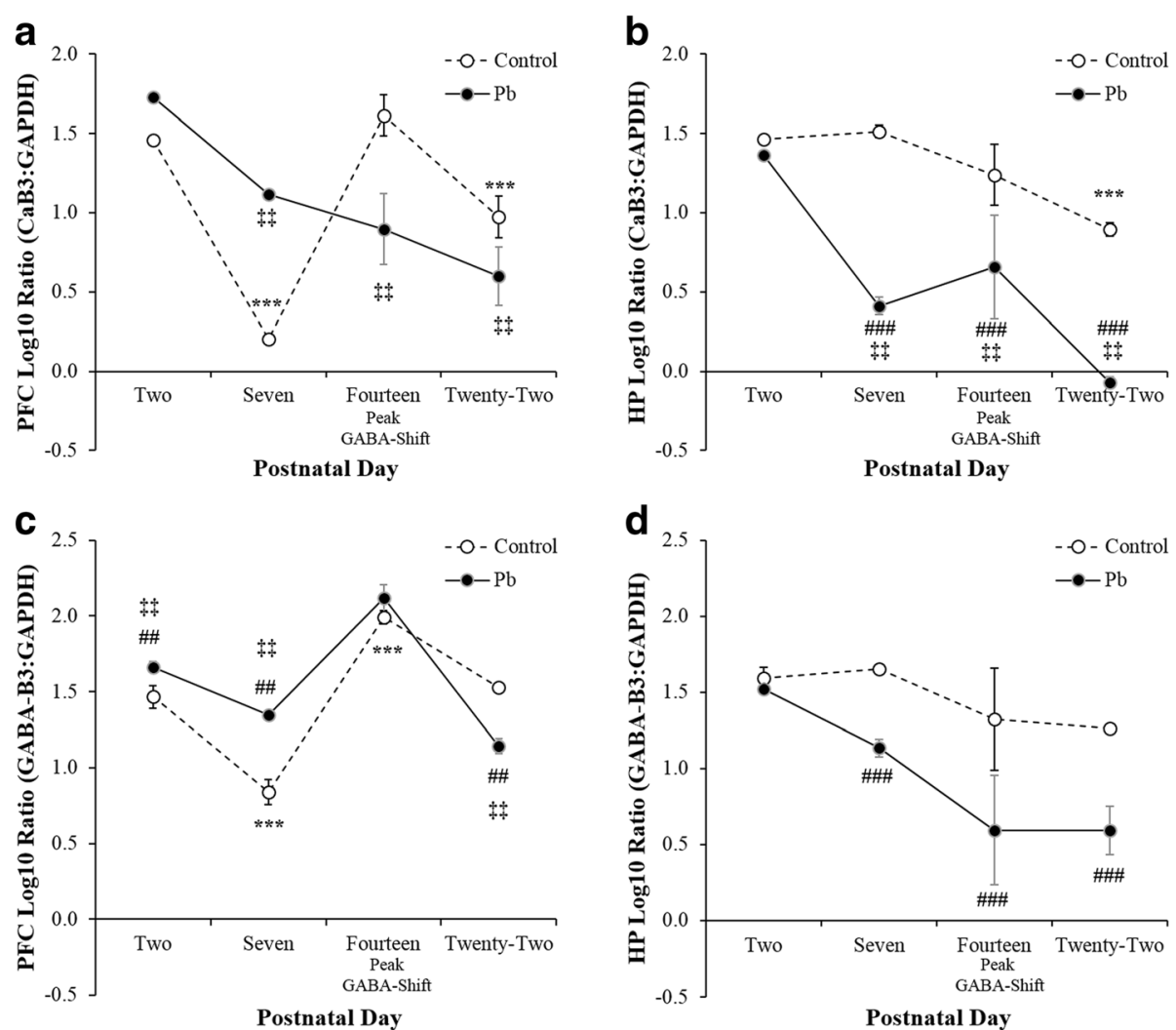

Fig. 1 Illustrates the PFC (a \& c) and HP (b \& d) neurodevelopmental expression of Ca- $\beta 3$ (upper panel) and GABA $A_{A R}-\beta 3$ (lower panel) mRNA between Control and $\mathrm{Pb}^{2+}$ exposed rats. Perinatal $\mathrm{Pb}^{2+}$ exposure alters the expression of $\mathrm{Ca}-\beta 3$ mRNA with increased vulnerability in the PFC at PND 7 and 14, and in the HP at PND 7 and 22. Pb ${ }^{2+}$ exposure resulted in an altered regulation of GABA $A_{A R}-\beta 3$ mRNA expression at PND 7 and 22 in the PFC and a down regulation from PND 7-22 in the HP. Data are presented as \pm SEM and Tukey's post hoc analyses are denoted as a significant difference in Control rats $\left(p<0.05^{*}, p<0.01^{* *}, p<0.001^{* * *}\right)$ as a function of Age, and denoted as a significant difference between $\mathrm{Pb}^{2+}$ vs. Control $\left(p<0.05^{\#}, p<0.01^{\# \#,}, p<0.001^{\# \#)}\right.$ ) as a function of Age and an Age $X$ Treatment interaction for each developmental time-point $\left(p<0.05^{\ddagger}, p<0.01^{\neq \ddagger}, p<0.001^{\neq \neq \ddagger}\right)$ 

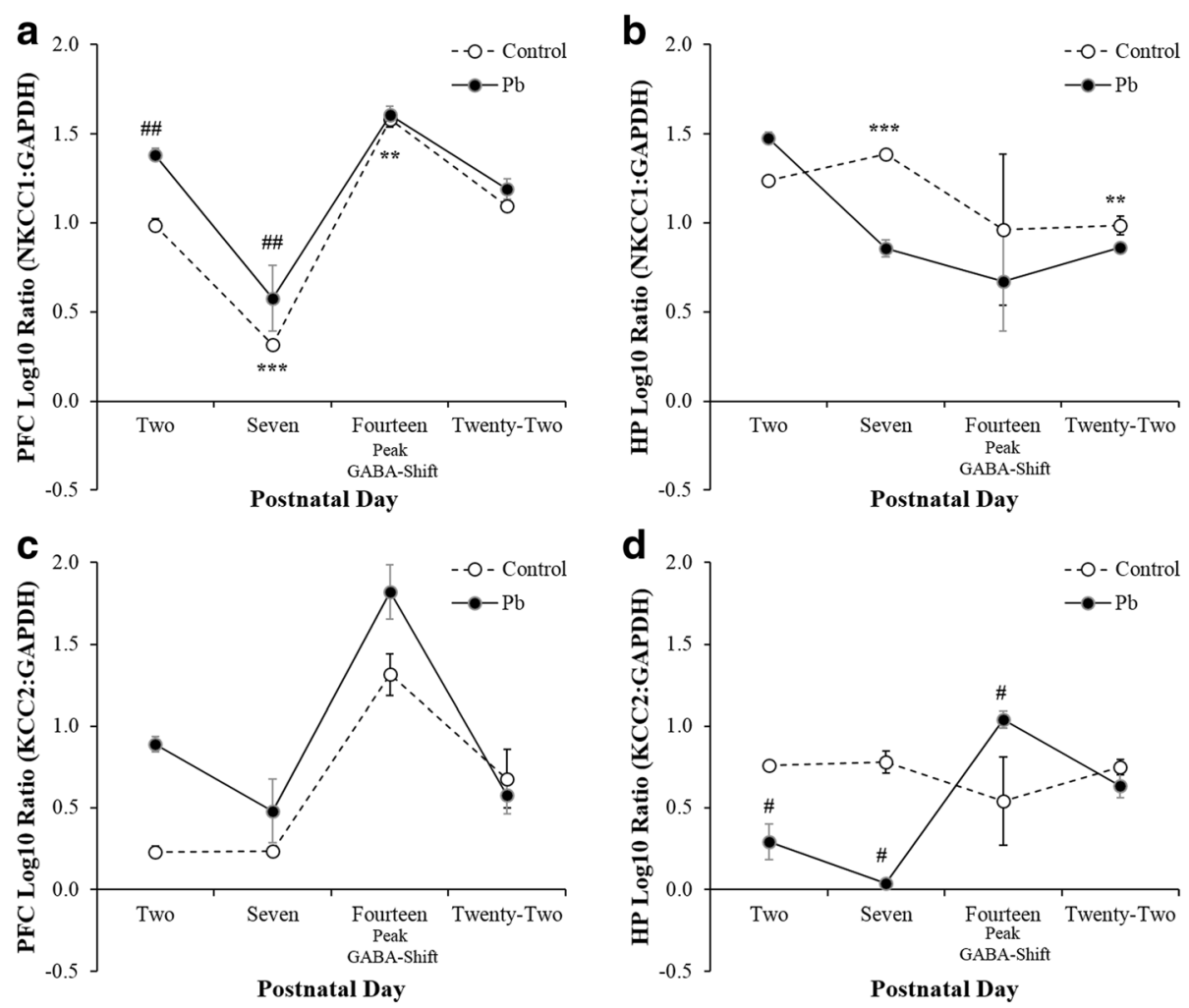

Fig. 2 Illustrates the PFC $(\mathbf{a} \& \mathbf{c})$ and HP (b \& d) neurodevelopmental expression of $\mathrm{NKCC}_{1}$ (upper panel) and $\mathrm{KCC}_{2}$ (lower panel) mRNA between Control and $\mathrm{Pb}^{2+}$ exposed rats. Perinatal $\mathrm{Pb}^{2+}$ exposure resulted in an upregulation of $\mathrm{NKCC}_{1}$ in the PFC at PND 2, whereas in the HP NKCC1 was slightly upregulated at PND 2 and down regulated at PND 7. At PND 2 and $14 \mathrm{KCC}_{2}$ was upregulated by Pb ${ }^{2+}$ exposure. However, $\mathrm{Pb}^{2+}$ exposure caused a down regulation of $\mathrm{KCC}_{2}$ mRNA expression at PND 2 and 7, followed by an upregulation at 14 in the HP. Data are presented as \pm SEM and Tukey's post hoc analyses are denoted as a significant difference in Control rats $\left(p<0.05^{*}, p<0.01^{* *}, p<0.001^{* *}\right)$ as a function of Age, and denoted as a significant difference between $\mathrm{Pb}^{2+}$ vs. Control $(p<0.05 \#, p<0.01 \# \#, p<0.001 \# \#)$ as a function of Age and an Age $X$ Treatment interaction for each developmental time-point $\left(p<0.05^{\ddagger}, p<0.01^{\neq \neq}, p<0.001^{\neq \neq \neq}\right)$

evidenced an Age X Treatment interaction $F_{(3,1,20)}=19.89, p$

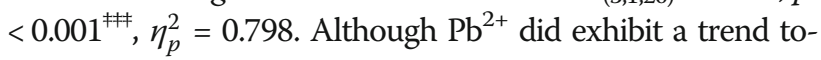
wards blunting the decrease in GABA- $\beta 3$ expression from PND 2 to 7, this change was not as dramatic as seen with $\mathrm{Ca} 33$ in PFC between these two time points. At PND 14, $\mathrm{Pb}^{2+}$ did not cause a further decrease in GABA- $\beta 3$ as it did for $\mathrm{Ca} \beta 3$; indeed expression recovered in a manner similar to control animals. GABA- $\beta 3$ mRNA levels showed a similar response to $\mathrm{Pb}^{2+}$ as $\mathrm{Ca} 33$ in $\mathrm{HP}$, levels were reduced at each time point examined (Fig. 1d) with a significant effect of Age $F_{(3,20)}=5.79, p<0.01^{* *}, \eta_{p}^{2}=0.521$ and a Treatment effect $F_{(1,20)}=14.52, p<0.001^{\# \# \#}, \eta_{p}^{2}=0.476$. Overall, the results show that $\mathrm{Pb}^{2+}$ treatment altered the expression levels of $\mathrm{Ca} \beta 3$ and GABA- $\beta 3$ at many developmental time points in both PFC and HP.

\section{$\mathrm{Pb}^{2+}$ effects on $\mathrm{NKCC}_{1}$ and $\mathrm{KCC}_{2}$ mRNA}

In control PFC, $\mathrm{NKCC}_{1}$ mRNA exhibited a biphasic regulation similar to that of $\mathrm{Ca}-\beta 3$ mRNA with downregulated expression as an Age effect $F_{(3,20)}=82.29$, $p<0.001 \% *, \eta_{p}^{2}=0.939$, at PND 7 that recovered by PND 14 to approximately the same levels at PND 2 (Fig. 2a). In contrast, to $\mathrm{Ca}-\beta 3$ however, there was a significant Treatment effect $F_{(1,20)}=13.75, p<0.01^{\# \#}, \eta_{p}^{2}=0.462$ with a notable increase in $\mathrm{NKCC}_{1}$ mRNA at PND 2 in the $\mathrm{Pb}^{2+}$ treated animals. In $\mathrm{HP}, \mathrm{NKCC}_{1}$ mRNA remained fairly constant, but evidenced a significant Age effect from PND 2 through $22 F_{(3,20)}=3.40, p<0.04^{*}, \quad \eta_{p}^{2}=0.389$ and $\mathrm{Pb}^{2+}$ treatment did not alter this expression profile to a significant extent (Fig. 2b). $\mathrm{KCC}_{2}$ mRNA in PFC exhibited a pattern of regulation similar to that of $\mathrm{NKCC}_{1}$ in control animals and this was not significantly altered in $\mathrm{Pb}^{2+}$ treated animals (Fig. 2c). Contrastingly in $\mathrm{HP}, \mathrm{KCC}_{2}$ mRNA was significantly downregulated in $\mathrm{Pb}^{2+}$ treated animals with an Age effect most notable at PND $7 F_{(3,19)}=3.95, p<0.03^{*}, \eta_{p}^{2}=$ 0.286 , with a Treatment effect $F_{(1,19)}=6.00, p<0.03^{\#}, \eta_{p}^{2}=$ 0.441 , and an Age X Treatment interaction $F_{(3,1,19)}=9.50$, $p<0.001^{f \neq \neq}, \eta_{p}^{2}=0.655$ (Fig. 2d). Overall, the results suggest a lesser, and perhaps indirect response, in mRNA 
regulation to $\mathrm{Pb}^{2+}$ for $\mathrm{NKCC}_{1}$ and $\mathrm{KCC}_{2}$ versus the significant direct changes in $\mathrm{Ca} \beta 3$ and GABA- $\beta 3$ mRNA in $\mathrm{Pb}^{2+}$ treated animals.

\section{$\mathrm{Pb}^{2+}$ effects on GAD 80/86 and 65/67 mRNA}

In PFC GAD 80 mRNA expression revealed a significant effect of Age $F_{(3,20)}=7.78, p<0.01^{* * *}, \eta_{p}^{2}=0.593$ and a Treatment effect $F_{(1,20)}=5.38, p<0.05^{\#}, \eta_{p}^{2}=0.252$ (Fig. 3a). We also observed similar outcomes in PFC GAD 86 mRNA with a significant effect of Age $F_{(3,20)}=19.09, p<0.001^{* * *}$, $\eta_{p}^{2}=0.782$, and a Treatment effect $F_{(1,20)}=16.25$, $p<0.001^{\# \# \#}, \eta_{p}^{2}=0.504$ (Fig. 3b). In contrast, HP GAD 80 mRNA revealed only an Age $X$ Treatment interaction $F_{(3,1,20)}=7.06, p<0.01^{\ddagger}, \eta_{p}^{2}=0.570$ (Fig. 3e). HP GAD 86 mRNA revealed only a significant effect of $\operatorname{Age} F_{(3,20)}=8.41$, $p<0.001^{* * * *}, \eta_{p}^{2}=0.612$ (Fig. 3f).

In PFC GAD 65 mRNA revealed a significant effect of Age $F_{(3,20)}=34.02, p<0.001^{* * * *}, \eta_{p}^{2}=0.864$ and an Age $X$ Treatment interaction $F_{(3,1,20)}=7.57, p<0.01^{\text {半 }}, \eta_{p}^{2}=0.587$ (Fig. 3c). Also, PFC GAD 67 mRNA revealed a significant effect of Age $F_{(1,20)}=13.05, p<0.001^{* * * *}, \eta_{p}^{2}=0.710$ and an Age $X$ Treatment interaction $F_{(3,1,20)}=16.21, p<0.001^{\text {f\#中 }}$, $\eta_{p}^{2}=0.752$ (Fig. 3d). In contrast, HP GAD 65 mRNA revealed only a significant effect of Treatment $F_{(1,19)}=5.90$, $p<0.05^{\#}, \eta_{p}^{2}=0.282$ (Fig. 3g). Also, HP GAD 67 mRNA revealed a significant effect of Age $F_{(3,19)}=3.95, p<0.05^{*}$,

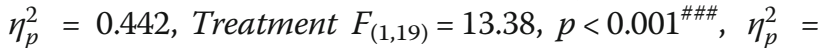
0.471, and an Age X Treatment interaction $F_{(3,1,19)}=8.95$, $p<0.001^{\text {执 }}, \eta_{p}^{2}=0.641$ (Fig. 3h). The overall outcomes of $\mathrm{Pb}^{2+}$ effects on the mRNA of key genes responsible for the GABA-shift are summarized in Table 2.

\section{Discussion}

The GABA-shift is a critical $\mathrm{Ca}^{2+}$-dependent neurodevelopmental process that is altered by perinatal $\mathrm{Pb}^{2+}$ exposure

There are two $\mathrm{Ca}^{2+}$-dependent genes critical for activating the neurodevelopmental GABA-shift: the Slc12a2 and Slc12a5 genes, which encode $\mathrm{NKCC}_{1}$ and $\mathrm{KCC}_{2}$, respectively. This $\mathrm{Cl}^{-}$-cotransporter gene family is

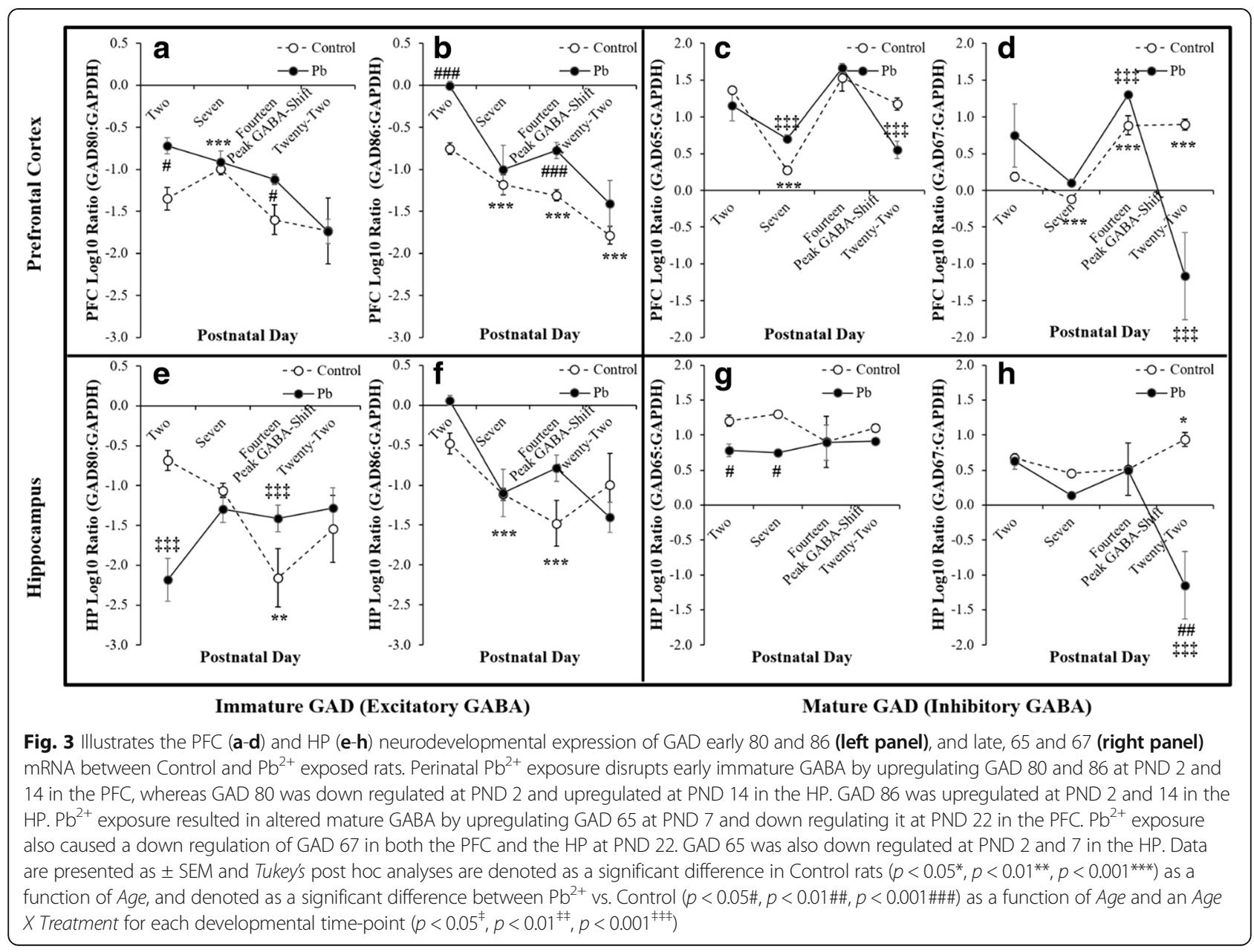


Table 2 Summary of perinatal $\mathrm{Pb}^{2+}$ exposure results on developmental time-points altering the expression of genes related to the GABA-shift, when compared to the Control group

\begin{tabular}{|c|c|c|c|c|c|c|c|c|}
\hline \multirow{3}{*}{$\frac{\text { Genes }}{\text { Caß3 }}$} & \multicolumn{4}{|c|}{ PFC $\mathrm{Pb}^{2+}$ Effects } & \multicolumn{4}{|c|}{$H P P b^{2+}$ Effects } \\
\hline & \multirow{2}{*}{$\begin{array}{l}\text { PND } 2 \\
\uparrow\end{array}$} & \multirow{2}{*}{$\begin{array}{l}\text { PND } 7 \\
\uparrow\end{array}$} & \multirow{2}{*}{$\frac{\text { PND } 14}{\downarrow}$} & \multirow{2}{*}{$\frac{\text { PND } 22}{\downarrow}$} & \multicolumn{2}{|c|}{ PND 2 PND 7} & \multirow{2}{*}{$\frac{\text { PND } 14}{\downarrow}$} & \multirow{2}{*}{$\frac{P N D 22}{\downarrow}$} \\
\hline & & & & & $\leftrightarrow$ & $\downarrow$ & & \\
\hline & $\mathrm{n} / \mathrm{s}$ & 㧊 & 㧊 & 㧊 & $\mathrm{n} / \mathrm{s}$ & 㧊 & 㧊 & 㧊 \\
\hline & & & & & & \#\#\# & \#\#\# & \#\#\# \\
\hline \multirow[t]{3}{*}{ GABA- $\beta 3$} & $\uparrow$ & $\uparrow$ & $\leftrightarrow$ & $\downarrow$ & $\leftrightarrow$ & $\downarrow$ & $\downarrow$ & $\downarrow$ \\
\hline & 㧊 & $\neq \neq$ & $\mathrm{n} / \mathrm{s}$ & 㧊 & $n / s$ & \#\#\# & \#\#\# & \#\#\# \\
\hline & \#\# & \#\# & & \#\# & & & & \\
\hline \multirow[t]{2}{*}{ NKCC1 } & $\uparrow$ & $\uparrow$ & $\leftrightarrow$ & $\leftrightarrow$ & $\uparrow$ & $\downarrow$ & $\leftrightarrow$ & $\downarrow$ \\
\hline & \#\# & \#\# & $\mathrm{n} / \mathrm{s}$ & $n / s$ & $n / s$ & $\mathrm{n} / \mathrm{s}$ & $\mathrm{n} / \mathrm{s}$ & $\mathrm{n} / \mathrm{s}$ \\
\hline \multirow[t]{2}{*}{ KCC2 } & $\uparrow$ & $\leftrightarrow$ & $\uparrow$ & $\leftrightarrow$ & $\downarrow$ & $\downarrow$ & $\uparrow$ & $\leftrightarrow$ \\
\hline & $n / s$ & $n / s$ & $n / s$ & $\mathrm{n} / \mathrm{s}$ & $\#$ & $\#$ & \#\# & $n / s$ \\
\hline \multirow[t]{2}{*}{ GAD-80 } & $\uparrow$ & $\leftrightarrow$ & $\uparrow$ & $\leftrightarrow$ & $\downarrow$ & $\leftrightarrow$ & $\uparrow$ & $\leftrightarrow$ \\
\hline & $\#$ & $\mathrm{n} / \mathrm{s}$ & $\#$ & $\mathrm{n} / \mathrm{s}$ & 㧊 & $n / s$ & 㧊 & $n / s$ \\
\hline \multirow[t]{2}{*}{ GAD-86 } & $\uparrow$ & $\leftrightarrow$ & $\uparrow$ & $\leftrightarrow$ & $\uparrow$ & $\leftrightarrow$ & $\uparrow$ & $\leftrightarrow$ \\
\hline & \#\#\# & $n / s$ & \#\#\# & $n / s$ & $n / s$ & $n / s$ & $n / s$ & $n / s$ \\
\hline \multirow[t]{2}{*}{ GAD-65 } & $\leftrightarrow$ & $\uparrow$ & $\leftrightarrow$ & $\downarrow$ & $\downarrow$ & $\downarrow$ & $\leftrightarrow$ & $\leftrightarrow$ \\
\hline & $\mathrm{n} / \mathrm{s}$ & 㧊 & $n / s$ & 㧊 & $\#$ & $\#$ & $n / s$ & $n / s$ \\
\hline \multirow[t]{3}{*}{ GAD-67 } & $\uparrow$ & $\uparrow$ & $\uparrow$ & $\downarrow$ & $\leftrightarrow$ & $\downarrow$ & $\leftrightarrow$ & $\downarrow$ \\
\hline & $\mathrm{n} / \mathrm{s}$ & $\mathrm{n} / \mathrm{s}$ & $\neq \neq \neq$ & 㧊 & $\mathrm{n} / \mathrm{s}$ & $\mathrm{n} / \mathrm{s}$ & $\mathrm{n} / \mathrm{s}$ & 㧊 \\
\hline & & & & & & & & \#\#\# \\
\hline
\end{tabular}

Note: Difference in expression of mRNAs are summarized as $(\uparrow)=$ an increase in mRNA, $(\downarrow)=$ a decrease in mRNA, and $(\leftrightarrow)=$ no difference in relative mRNA expression.

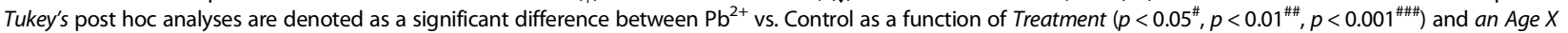
Treatment interaction $\left(p<0.05^{\ddagger}, p<0.01^{\ddagger \neq}, p<0.001^{\ddagger \neq \neq}\right)$ for each developmental time-point, whereas $(\mathrm{n} / \mathrm{s})=$ not significant

responsible for maintaining cell volume regulation, epithelial transport, and GABAergic circuitry $[17,18]$. The latter sets the neurodevelopmental sequences for precise $\mathrm{Ca}^{2+}$ wave oscillations driving GABAergic GDPs [11, 12], which regulate $\mathrm{Ca}^{2+}$-dependent gene signaling [19]. In the present study, it was hypothesized that perinatal $\mathrm{Pb}^{2+}$ treatment during perinatal development in the rat model would disrupt $\mathrm{Ca}^{2+}$-dependent gene signals, causing altered PFC and HP mRNA neurodevelopmental expression patterns. The data suggest that the coordination of this critical neurodevelopmental process is examinable through $\mathrm{Ca}-\beta 3$, GABA- $\beta 3$, and $\mathrm{NKCC}_{1} /$ $\mathrm{KCC}_{2}$ mRNA expression patterns as a function of postnatal age (Fig. 1). $\mathrm{Pb}^{2+}$ altered PFC Ca- $\beta 3$ mRNA expression through an upregulation at PND 7 and a down regulation at PND 14, whereas GABA- $\beta 3$ mRNA expression was significantly upregulated at PND 7 and down regulated at $\mathrm{PND} 22$. Contrastingly, $\mathrm{Pb}^{2+}$ down regulated HP Ca- $\beta 3$ mRNA expression at PND 7 and 22, whereas GABA- $\beta 3$ mRNA expression was down regulated at PND 7 and 22. Thus, in both the PFC and HP, these genes were differentially altered by gestational $\mathrm{Pb}^{2+}$ exposure. Interestingly, HP Ca- $\beta 3$ and GABA- $\beta 3$ mRNA expression were more sensitive to $\mathrm{Pb}^{2+}$ than the PFC. It remains to be determined whether different neurodevelopmental GABA-shift trajectories exist for other brain areas.

\section{$\mathrm{Pb}^{2+}$ differentially alters the $\mathrm{NCKK}_{1} / \mathrm{KCC}_{2} \mathrm{GABA}$-shift in the PFC \& HP}

Perinatal $\mathrm{Pb}^{2+}$ exposure differentially altered the normal age-dependent $\mathrm{NKCC}_{1} / \mathrm{KCC}_{2}$ mRNA expression pattern in the PFC and HP (Fig. 2). In the PFC, at PND 2 $\mathrm{NKCC}_{1}$ mRNA expression was significantly upregulated (Fig. 2a) and at PND 2 and 14 the $\mathrm{KCC}_{2}$ mRNA expression was significantly upregulated (Fig. 2c). Interestingly, in the HP $\mathrm{NKCC}_{1}$ mRNA expression was upregulated at PND 2 and down regulated at PND 7 (Fig. 2b). However, the $\mathrm{HP} \mathrm{KCC}_{2}$ mRNA expression was down regulated at PND 2 and 7 then upregulated at PND 14 (Fig. $2 \mathrm{~d})$. The pattern of $\mathrm{NKCC}_{1} / \mathrm{KCC}_{2}$ mRNA expression was different between the PFC (i.e., $\mathrm{NKCC}_{1}$ vulnerability) and the $\mathrm{HP}$ (i.e., $\mathrm{NKCC}_{1} / \mathrm{KCC}_{2}$ vulnerability). Notably, the PFC and $\mathrm{HP} \quad \mathrm{NKCC}_{1} / \mathrm{KCC}_{2}$ mRNA expression returned to control levels at PND 22 (Fig. 2). These neurodevelopmental $\mathrm{NKCC}_{1 /} \mathrm{KCC}_{2}$ mRNA alterations underlie a molecular basis for 
increasing brain excitability in response to $\mathrm{Pb}^{2+}$ exposure, by two potential mechanisms: 1) prolonging early GABAergic excitation into adulthood or 2) delaying the onset of the mature inhibitory GABAergic system. Our data suggests that different brain regions may have unique neurodevelopmental time courses of $\mathrm{NKCC}_{1} / \mathrm{KCC}_{2}$ expression patterns [19-24] that may prove useful in early molecular diagnostic testing in clinical neurotoxicology.

\section{GAD isoforms provide unique insight into $\mathrm{Pb}^{2+}$ alterations of neurodevelopment}

The early GAD isoforms 80/86 regulating the immature GABAergic excitatory system occur in embryonic development, whereas the late GAD isoforms 65/67 regulating the mature GABAergic inhibitory system occur in gestation and persist across the lifespan $[25,26]$. The PFC GAD 80 mRNA and 86 mRNA expression were significantly affected by $\mathrm{Pb}^{2+}$ with upregulations at PND 2 and 14 (Fig. 3a-b), whereas the HP GAD 80/86 mRNA expression were not significantly affected by $\mathrm{Pb}^{2+}$ treatment, yet showed a down regulation for GAD 80 at PND 2 (Fig. 3e-f). The PFC GAD 65/67 mRNA expression were significantly down regulated at PND 22 and GAD 65 was down regulated at PND 7 in response to Perinatal $\mathrm{Pb}^{2+}$ treatment (Fig. 3c-d). The HP GAD 80 expression was significantly down regulated at PND 2 (Fig. 3b). However, the HP mRNA expression for GAD 65 was down regulated at PND 2 and 7, whereas the GAD 67 mRNA expression was significantly down regulated at PND 22 (Fig. 3g-h). The data suggest that $\mathrm{Pb}^{2+}$ exposure disrupted GAD 80/86 expression in the PFC and the HP during the gestational period with persisting impacts that were observed at PND 2 and its later life relationship with GAD 65/67 at PND 22 (Fig. 3). The findings from the present study, offer a novel mechanism for evaluating GAD isoforms in conjunction with the $\mathrm{NKCC}_{1} / \mathrm{KCC}_{2} \mathrm{GABA}$-shift transporters in assessing developmental $\mathrm{Pb}^{2+}$ neurotoxicology. This mechanism may prove informative for screening other developmental neurotoxicants other than $\mathrm{Pb}^{2+}$.

\section{GABA-shift disruption and developmental neuropathology}

In the mature brain, the two major neurotransmitters $\gamma$-amino butyric acid (GABA) and glutamic acid (Glutamate), balance neural excitability. However, the immature GABAergic system is initially excitatory prior to the functional activation of the glutamatergic system. Whereby this switch is neurodevelopmentally regulated by $\mathrm{NKCC}_{1} / \mathrm{KCC}_{2}$ expression and functional activation $[11,12]$. Notably, $\mathrm{NMDA}_{\mathrm{R}}$ perturbations induced by perinatal $\mathrm{Pb}^{2+}$ exposure are known to contribute to lifelong intellectual disability $[27,28]$, but occur following the GABA-shift. However, the present study argued that given the functional silence of the $\mathrm{NMDA}_{\mathrm{R}}$ system prior to GABAergic-dependent GDP activation [11, 12], that the GABAergic system may be more vulnerable to gestational and the Glutamatergic system to postnatal $\mathrm{Pb}^{2+}$ exposures. Alternatively, glutamatergic $\mathrm{NMDA}_{\mathrm{R}}$ disruption may be a secondary consequence of $\mathrm{Pb}^{2+}$ exposure following early disruption of GABAergic excitation, $\mathrm{NKCC}_{1} / \mathrm{KCC}_{2}$ transporters, and GAD 80/86 and $65 / 67$ interrelated events. Altogether, these findings implicate that clinical assessment of BLLs in children within the first year of life may be useful in determining gestational and postnatal neurodevelopmental risks associated with the maturation of the GABAergic system. Additionally, early neurodevelopmental $\mathrm{Pb}^{2+}$ poisoning can disrupt the predetermined pattern of genetic events that promote adequate myelination and synaptogenesis, which is most critical in the child's early years [29]. Early disruption of these predetermined genetic events can result in a child deviating, disassociating, of disrupting the nature of typical human development and its accompanying milestones [30]. Essentially, it can be argued that consistent and appropriate early $\mathrm{Pb}^{2+}$ detection in children's BLLs may be a valuable predictor of an altered inhibitory neurobehavioral profile in the child. Therefore, further study is warranted to elucidate GABAergic neurodevelopmental outcomes in response to $\mathrm{Pb}^{2+}$ insult producing developmental critical periods susceptible for acquiring neuropathological conditions prior to functional activation and involvement of the Glutamatergic system.

\section{Conclusion}

In summary, this study shows that perinatal $\mathrm{Pb}^{2+}$ exposure through parturition can cause GABAergic neurodevelopmental alterations in the GOIs patterns of expression that regulate the GABA-shift through disruption of L-Type VSCCs signaling. Such aberrant neural excitability may cause either activity-dependent delays or premature switches of the $\mathrm{NKCC}_{1} / \mathrm{KCC}_{2}$ transporters dysregulating the GABA-shift in neurodevelopment, which are critical for establishing appropriate GABAergic networks within and across brain regions [17-25, 31-34]. The PFC and the HP were selected since the HP has been the brain region specifically studied in association with the GABA-shift in neurodevelopment $[11,12]$ and less is known regarding the PFC. Further, within the brain the PFC, HP and the cerebellum are most vulnerable for lead-induced brain damage as each region accumulates more lead deposition than other brain regions in clinical studies of children [36]. Thus, since less the PFC and its relationship with the $\mathrm{HP}$ are vulnerable to $\mathrm{Pb}^{2+}$ exposure during critical stages of neurodevelopment and they 
regulate higher order cognitive processes regarding frontoexecutive functions in contrast to the cerebellum, the study revealed that perinatal lead exposure could alter the expression of mRNA from genes involved in the GABA-shift. The clinical implications of these findings suggest that early developmental $\mathrm{Pb}^{2+}$ exposure may significantly alter the brains GABAergic networks, which may in turn, alter the developmental time-course of expression of the maturing inhibitory system. Thus, further work is required in describing the extent to which these observed mRNA altered expression patterns relate with physiological and behavioral changes in the effected individual. Results from perinatal $\mathrm{Pb}^{2+}$ exposure animal models have shown consistently deficits of inhibitory regulated behaviors across the lifespan, corroborating with the findings presented in this study. Further, such GABA-shift alterations can perhaps induce an array of brain excitability problems, increasing the susceptibility risks for incurring a spectrum of developmental neuropathologies that will persist across the lifespan. It is important to note that the GABA-Peak-Shift (as noted on each of the graphs at PND 14 on the data presented herein) are based solely on observations of the HP and one must be cautious in assuming that all brain regions follow the same time-periods of peak GABA-shifting. As such, the data presented in this study suggest that the PFC may have its own unique peak GABA-shift time-period from that of the HP. Moreover, perinatal $\mathrm{Pb}^{2+}$ exposure alters the normal age-dependent trajectory of the GABA-shift GOIs differentially dependent upon the brain region. This suggests that each brain region may "shift" at distinct time-periods of development and may equally present with neurotoxicant susceptibilities resulting in developmental neuropathologies during these precise time-periods. As such, $\mathrm{Pb}^{2+}$ exposure competes with critical $\mathrm{Ca}^{2+-}$ dependent gene activity dysregulating the GABA-shift as a model of neurological disease $[34,36]$ consistent with reports by Khale et al. [21], and Hyde et al. [35].,Moreover, neurodevelopmental $\mathrm{Pb}^{2+}$ exposure in children lacks an early developmental behavioral signature, yet interestingly neurocognitive patterns of impairments can be assessed later in life under behavioral learning and memory conditions [34, 36]. Further, it has been shown that $\mathrm{NMDA}_{\mathrm{R}}$ blockade by $\mathrm{Pb}^{2+}$ and MK-801 can directly impair the acquisition learning [37, 38], but MK-801 antagonism has also been shown to impede the expression of inhibitory learning across the lifespan [39]. This suggests that neurodevelopmental $\mathrm{Pb}^{2+}$ exposure may cause similar dysfunctions in the expression of GABAergic-dependent learning. Thus, perinatal $\mathrm{Pb}^{2+}$ exposure can produce either GABAergic neurodevelopmental delays or suppression of neurotypical developmental gene expression patterns in the PFC and HP which can contribute and/or establish intellectual disabilities across the lifespan.

\section{Abbreviations}

ASV: Anodic stripping voltammetry; BLL: Blood lead level; Ca- 33 : L-Type voltage sensitive calcium channel-beta-3 subunit; GABA- $\beta 3$ : $\gamma$-amino butyric acid A-beta-3 receptor subunit; GAD: Glutamic acid decarboxylase;

GAPDH: Glyceraldehyde-3-phosphate dehydrogenase; HP: Hippocampus; $\mathrm{KCC}_{2}$ : Potassium/chloride co-transporter; $\mathrm{NKCC}_{1}$ : Sodium/potassium chloride co-transporter; PFC: Prefrontal cortex; PND: Postnatal day; RBC: Red blood cell

\section{Funding}

The work was supported in part by NSF Grant (AGEP \# 0450360) and Louis Strokes Alliance for Minority Participation (LSAMP) awards to LSN.

\section{Availability of data and materials}

The datasets used and/or analyzed during the current study are available from the corresponding author on reasonable request.

\section{Authors' contributions}

Conceived of the experiment: LSN and AE. Conducted the experiment: LSN. Analyzed the data and wrote the manuscript: LSN, GRP, and AE. All authors read and approved the final manuscript.

\section{Ethics approval and consent to participate}

The present study was conducted in compliance and accordance with the College of Staten Island IACUC and received the necessary ethics approval by the committee.

\section{Competing interests}

The authors declare that they have no competing interests.

\section{Publisher's Note}

Springer Nature remains neutral with regard to jurisdictional claims in published maps and institutional affiliations.

\section{Author details}

${ }^{1}$ Department of Psychology, SUNY Old Westbury, 223 Store Hill Road, Bldg.: NAB, Room: 2059, Old Westbury, NY 11568-1700, USA. 'SUNY Old Westbury, Neuroscience Research Institute, 223 Store Hill Road, Bldg.: NAB, Room: 2059, Old Westbury, NY 11568-1700, USA. ${ }^{3}$ Department of Biology, The College of Staten Island (CUNY), Staten Island, NY 10314, USA. ${ }^{4}$ The CUNY Graduate Center, Biology Program, New York, NY 10016, USA. ${ }^{5}$ The Center for Developmental Neuroscience, Staten Island, NY 10314, USA.

Received: 20 January 2018 Accepted: 18 May 2018

Published online: 24 May 2018

\section{References}

1. Royce, S.E. Case Studies in Environmental Medicine: Lead Toxicity. ATSDR, Atlanta: U.S. Department of Health and Human Services, 8;1992.

2. Lidsky TI, Schneider JS. Lead neurotoxicity in children: basic mechanisms and clinical correlates. Brain. 2003;126:5-19.

3. Schneider JS, Anderson DW, Talsania K, Mettil W, Vadigepalli R. Effects of developmental lead exposure on the hippocampal transcriptome: influences of sex, developmental period, and lead exposure level. Toxicol Sci. 2012;129(1):108-25.

4. Schneider JS, Anderson DW, Sonnenahalli H, Vadigepalli R. Sex-based differences in gene expression in hippocampus following postnatal lead exposure. Toxicol Appl Pharmacol. 2011;256:179-90.

5. Anderson DW, Mettil W, Schneider JS. Rearing environment, sex and developmental lead exposure modify gene expression in the hippocampus of behaviorally naïve animals. Neurochem Int. 2013;64(4):510-20.

6. Guilarte TR, McGlothan JL. Hippocampal NMDA receptor mRNA undergoes subunit specific changes during developmental lead exposure. Brain Res. 1998;790:98-107.

7. Guilarte TR, McGlothan JL, Nihei MK. Hippocampal expression of N-methlyD-aspartate receptor (NMDAR1) subunit splice variant mRNA is altered by developmental $\mathrm{Pb}^{2+}$ exposure. Mol Brain Res. 2000;76:299-305.

8. Guilarte TR, McGlothan JL. Selective decrease in NR1 subunit splice variant mRNA in the hippocampus of $\mathrm{Pb}^{2+}$-exposed rats: implications for synaptic targeting and c surface expression of NDMAR complexes. Mol Brain Res. 2003;113:37-43. 
9. Lanphear BP, Dietrich K, Auinger P, Cox C. Cognitive deficits associated with blood lead concentrations $<10 \mu \mathrm{g} / \mathrm{dL}$ in US children and adolescents. Public Health Rep. 2000;115:521-9.

10. Lidsky Tl, Schneider JS. Adverse effects of childhood lead poisoning: the clinical neuropsychological perspective. Environ Res. 2006;100:284-93.

11. Ben-Ari Y. Excitatory actions of GABA during development: the nature or the nurture. Nat Rev Neurosci. 2006;9:728-39.

12. Ben-Ari Y, Khalilov I, Kahle KT, Cherubini E. The GABA excitatory/inhibitory shift in brain maturation and neurological disorders. Neuroscientist. 2012:1-20.

13. Gomez-Ospinosa N, Tsuruta F, Barreto-Chang O, Hu L, Dolmetsch R. The C terminus of the L-type voltage gated calcium channel Cav $\mathrm{V}_{1.2}$ encodes a transcription factor. Cell. 2006;127:591-606.

14. Klugbauer N, Welling A, Specht V, et al. L-type ca(2+) channels of the embryonic mouse heart. Eur J Pharmocol. 2002;447:279-84.

15. Zhang A, Shen CH, Ma SY, Ke Y, El Idrissi A. Altered expression of autismassociated genes in the brain of fragile $X$ mouse model. Biochem Biophys Res Commun. 2009;379:920-3.

16. Shen CH, Lempert E, Butt I, Neuwirth LS, Yan X, El Idrissi A. Changes in gene expression at inhibitory synapses in response to taurine treatment. In: El Idrissi A, L'Amoreaux W, editors. Taurine 8: physiological roles and mechanisms of action, vol. 775. New York: Springer Press; 2013. p. 187-94.

17. Kahle KT, Rinehart J, Lifton RP. Phosphoregulation of the Na-K-2Cl cotransporters by the WNK kinases. Biochem Biophys Acta. 2012;1802(12): $1150-8$.

18. Kahle KT, Rinehart J, de los Heros P, Louvi A, Meade P, Vazquez N, et al. WNK3 modulates of $\mathrm{Cl}^{-}$transport in and out of cells: implications for control of cell volume and neuronal excitability. Proc Natl Acad Sci U S A. 2005;102: 16783-8.

19. Ganguly K, Schinder AF, Wong ST, Poo M. GABA itself promotes the developmental switch of neuronal GABAergic responses from excitation to inhibition. Cell Press. 2001;105:521-32.

20. Gamba G. Molecular physiology and pathophysiology of electroneutral cation chloride cotrans-porters. Physiol Rev. 2005;85:423-93.

21. Kahle KT, Staley KJ, Nahed BV, Gamba G, Hebert SC, Lifton RP, Mount DB. Roles of the cation-chloride cotransporters in neurological disease. Nature Clin Prac Neurol. 2008;4(9):490-503.

22. Lu J, Karadsheh $M$, Delpire E. Developmental regulation of the neuronalspecific isoform of K-cl cotransporter KCC2 in postnatal rat brains. J Neurobiol. 1999;39:558-68.

23. Rinehart J, Maksimova YD, Tanis JE, Stone KL, Hodson CA, Zhang J, et al. Sites of regulated phosphorylation that control K-cl cotransporter activity. Cell. 2009;138:525-36.

24. Rivera C, Voipio J, Payne JA, Ruusuvuori E, Lahtinen H, Lamsa K, Pirvola U, Saarma M, Kaila K. The K+/Cl- co-transporter KCC2 renders GABA hyperpolarizing during neuronal maturation. Nature. 1999;397:251-6.

25. Sun $Q$, Tian E, James-Turner $R$, Ten-Hagen KG. Developmental and functional studies of the SIC12 gene family members from drosophila melanogaster. Am J Physiol Cell Physiol. 2010;298:C26-37.

26. Szabo G, Katarova Z, Greenspan R. Distinct protein forms are produced from alternatively spliced bicistronic glutamic acid decarboxylase mRNAs during development. Mol Cell Biol. 1994;14(11):7535-45.

27. Toscano CD, Hashemzadeh-Gargari H, McGlothan JL, Guilarte TR. Developmental $\mathrm{Pb}^{2+}$-exposure alters NMDAR subtypes and reduces CREB phosphorylation in the rat brain. Brain Res Dev Brain Res. 2002;139:217-26.

28. Toscano CD, Guilarte TR. Lead neurotoxicity: from exposure to molecular effects. Brain Res Rev. 2005;49:529-54.

29. Myers SM. Diagnosing Developmental Disabilities. In: Batshaw ML, Rosen NJ, Lotrecchiano GR, editors. Children with disabilities. 7th ed. Baltimore: Paul H. Brookes Publishing Co; 2013.

30. Volpe J. Neurology of the newborn. 5th ed. Philadelphia: W.B. Saunders; 2008.

31. Vitari AC, Thastrup J, Rafiqi FH, Deak M, Morrice NA, Karlsson HKR, et al. Functional interactions of the SPAK/OSR1 kinases with their upstream activator WNK1 and downstream substrate NKCC1. Biochem J. 2006;397:223-31.

32. Vu TQ, Payne JA, Copenhagen DR. Localization and developmental expression patterns of the neuronal $\mathrm{K}-\mathrm{Cl}$ co-transporter (KCC2) in the rat retina. J Neurosci. 2000;20:1414-23.

33. Wake H, Watanabe M, Moorhouse AJ, Kanematsu T, Horibe S, Matsukawa N, et al. Early changes in KCC2 phosphorylation in response to neuronal stress result in functional downregulation. J Neurosci. 2007;27:1642-50.
34. Neuwirth, L.S. The characterization of $\mathrm{Pb}^{2+}$ toxicity in rat neural development: an assessment of $\mathrm{Pb}^{2+}$ effects on the GABA shift in neural networks and implications for learning and memory disruption. UMI Proquest Dissertations \& Theses 3612469. DAI/B 75-06(E), 2014

35. Finklestein Y, Markowitz ME, Rosen JF. Low-level lead-induced neurotoxicity in children: an update on central nervous system effects. Brain Res Rev. 1998;27:168-76

36. Neuwirth LS, Volpe NP, Corwin C, Ng S, Madan N, Ferraro AM, Furman Y, El Idrissi A. Taurine recovery of learning deficits induced by developmental $\mathrm{Pb}^{2+}$ exposure. In: Lee DH, Shaffer S, Park E, Kim HW, editors. Taurine 10: taurine and brain health, vol. 975. New York: Springer Press; 2017. p. 39-55. https://doi.org/10.1007/978-94-024-1079-2_4.

37. Hyde TM, Lipska BK, Ali T, Matthew SV, Law AJ, Metitiri OE, Straub RE, Ye T, Colantuoni C, Hermna MM, Bigelow LB, Weinberger DR, Kleinman JE. Expression of GABA signaling molecules KCC2, NKCC1, and GAD1 in cortical development and schizophrenia. J Neurosci. 2001;31(30):11088-95.

38. Liu J, Shi L, Wan B, Li B. Effects of chronic exposure to lead on long-term potentiation in hippocampal CA1 area on young rats in vivo. Chin J Prev Med. 2000;34(1):34-6.

39. Gökhan N, Neuwirth LS, Meehan EF. The effects of low dose MK-801 administration on $\mathrm{NMDA}_{\mathrm{R}}$ dependent executive functions in pigeons. Physiol Behav. 2017:173:243-51.

\section{Ready to submit your research? Choose BMC and benefit from:}

- fast, convenient online submission

- thorough peer review by experienced researchers in your field

- rapid publication on acceptance

- support for research data, including large and complex data types

- gold Open Access which fosters wider collaboration and increased citations

- maximum visibility for your research: over $100 \mathrm{M}$ website views per year

At BMC, research is always in progress.

Learn more biomedcentral.com/submissions 